\title{
Influence of ground water extraction in the seismic hazard of Mexico City
}

\author{
J. Avilés ${ }^{1}$, L. E. Pérez-Rocha ${ }^{2}$ \& H. R. Aguilar $^{3}$ \\ ${ }^{1}$ Instituto Mexicano de Tecnología del Agua, Mexico \\ ${ }^{2}$ Instituto de Investigaciones Electricas, Mexico \\ ${ }^{3}$ Centro de Investigación Sísmica, FJBS, Mexico
}

\begin{abstract}
The influence of ground water extraction in the seismic hazard of Mexico City is examined. Available information on settlements of the land surface is used to evaluate the subsidence effects on the predominant ground period. Microzoning maps, as a function of this relevant site parameter, are constructed for the present and future geotechnical conditions. Based on these maps, site-specific design spectra throughout the whole city are determined by applying seismic code provisions. It is found that the regional subsidence will generally be beneficial for structures with fundamental period longer that the current period of the site, but detrimental if the structure period is shorter than the site period.

Keywords: design spectra, ground water extraction, microzoning map, regional subsidence, seismic hazard.
\end{abstract}

\section{Introduction}

Extensive ground-water exploitation has been identified as the main cause of land subsidence in Mexico City. The phenomenon has caused large settlements in the past, up to $10 \mathrm{~m}$ at some areas of the city. Subsidence of the city was studied for the first time by Carrillo [1], showing a clear dependence with the amount and rate of water extraction from artesian wells. Since then, many efforts have been made to understand the phenomenon and mitigate its consequences. A review of these efforts can be found in Ovando-Shelley et al. [2]. These authors have studied the consolidation process in the central part of the city using the well-known Terzaghi's consolidation theory. They showed that exploitation of the aquifers under the lacustrine clays is reflected not only on the gradual 
reduction of their thickness, but also on the modification of their mechanical properties.

In Mexico City, ground motion amplification during earthquakes is the most important factor associated to the subsoil characteristics. The sedimentary basin measures approximately $30 \times 70 \mathrm{~km}$ and the thickness of compressible clay deposits may exceed $70 \mathrm{~m}$. With shear wave velocities ranging from around 50 to $100 \mathrm{~m} / \mathrm{s}$, the predominant ground period can be as long as $5 \mathrm{~s}$. In view of these geotechnical conditions, the resonant spectral acceleration for sites with dominant period around $2 s$ may reach up to one $g$ when intense subduction earthquakes occur as far as $300 \mathrm{~km}$. This was observed during the great 1985 Michoacan earthquake. Any variation in the present geotechnical conditions, however, will result in a change in the seismic hazard in the future.

In this work, an empirical method to predict the effects of regional subsidence on the seismic hazard in Mexico City for the coming years is presented. Using available information regarding precise leveling of benchmarks and geotechnical soil profiles, Aguilar et al. [3] have found correlations of the subsidence rate and the thickness of sediments with the predominant ground period. With the use of these data in a year-by-year incremental procedure, the evolution of the microzoning map and the corresponding design spectra specified by the building code, both in terms of the site period, is predicted for an exposure period of 50 years. This would allow the designer to evaluate the effects of regional subsidence during the life span of a structure.

\section{Available information}

The subsidence of Mexico City is studied here by using an empirical method based on extrapolating available data for predicting future trends. With spectral amplification functions for about 100 instrumented soft sites at Mexico City, complemented with around 500 microtremor measurements, predominant ground periods $T_{s}$ were computed for a rectangular grid of 80x80 points covering most part of the city, using the interpolation technique devised by PérezRocha et al [4]. This resulted in the microzoning map displayed in fig. 1, which will be referred hereafter as the 2000 version. The isoperiod curves for $T_{s}=0.5$ and $1 s$ roughly mark the separations between both the firm and transition zones as well as the transition and soft zones, respectively.

For about 360 sites, the thickness of sediments $H_{s}$ is also known. Fig. 2 lefthand side shows the correlation of this parameter with the site period obtained by Aguilar et al. [3]. This relationship is expressed by

$$
H_{s}(m)=31\left[T_{s}(s)-0.5\right]^{1 / 2} \text { for } T_{s} \geq 1 s
$$

Note that, for a given site, the shear wave velocity $V_{s}$ is defined indirectly by eqn. (1) since, according to the one-dimensional wave propagation theory, the expression $T_{s}=4 H_{s} / V_{s}$ applies. 


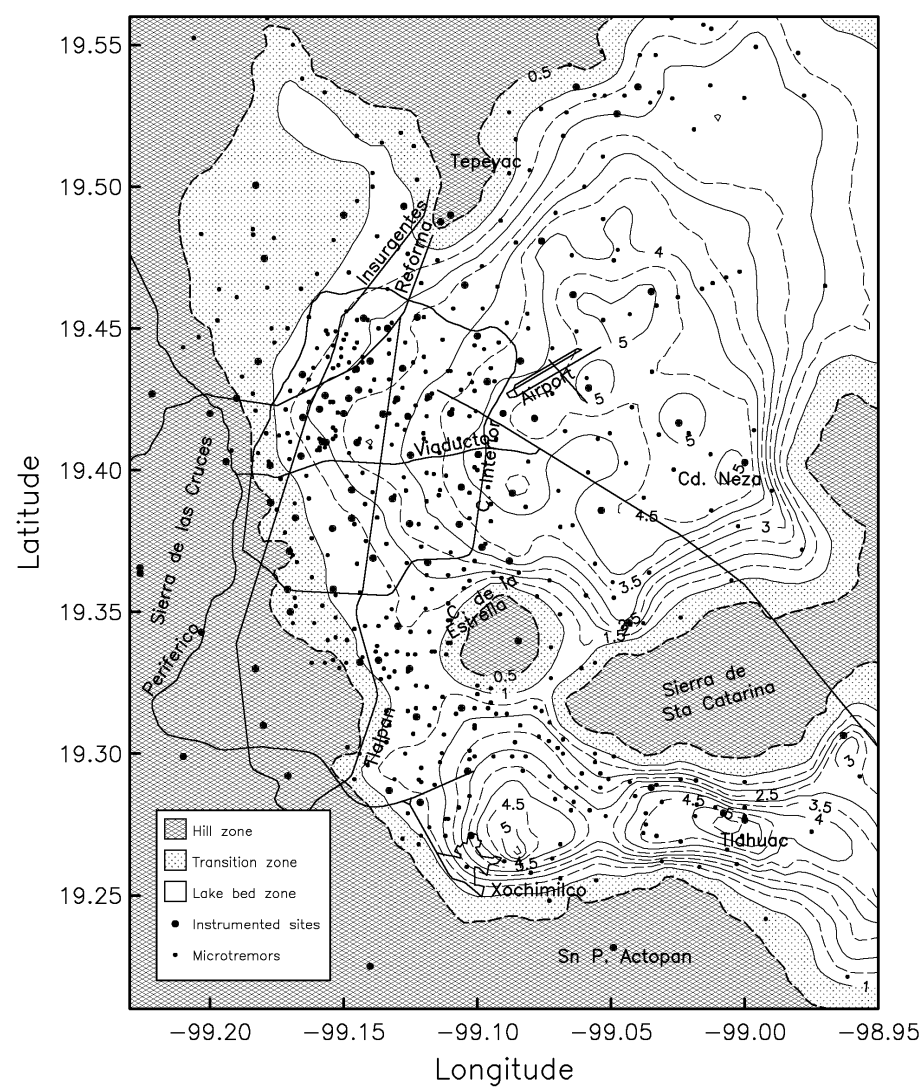

Figure 1: Curves of predominant ground period $(s)$ in Mexico City.

For monitoring subsidence in Mexico City, a network of more than 2200 benchmarks distributed along the city has been installed. This network was releveled in 1983 for the last time. By collecting elevation measurements at land surface during the time period 1983-1998, Aguilar et al. [3] estimated the amount of subsidence at soft sites. Then, the mean subsidence rate was correlated with the site period by the expression

$$
\mathrm{v}_{s}(\mathrm{~cm} / \text { year })=2\left[T_{s}(s)\right]^{1.9} \text { for } T_{s} \geq 1 s
$$

Fig. 2 right-hand side illustrates that the subsidence rate declines as the site period shortens which in turn occurs when the depth of sediments shrinks (see Fig. 2 left-hand side). This is consistent with the consolidation process in the lakebed zone of the city. It should be mentioned that the observed subsidence include not only the effect of ground-water extraction, but also the consolidation from the own weight of buildings. 

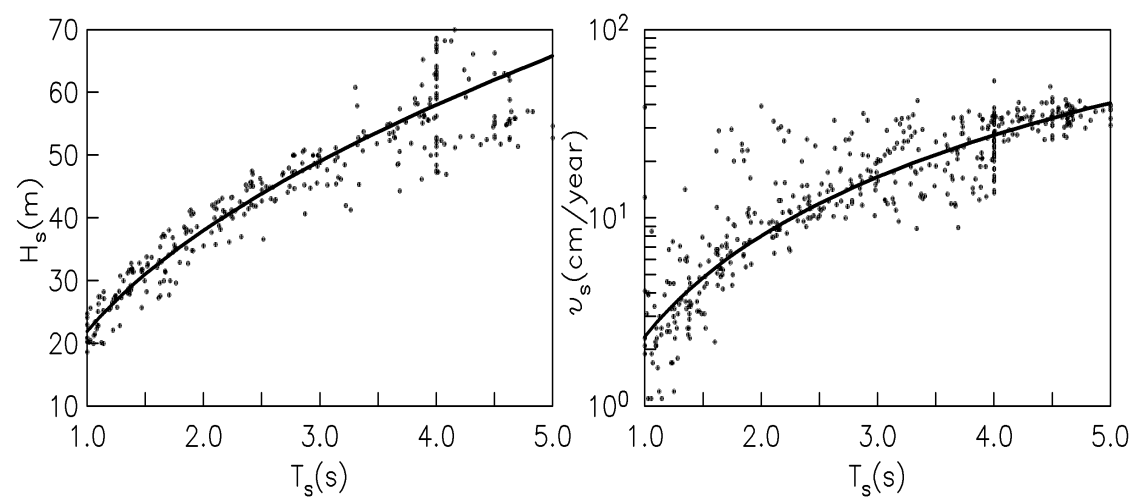

Figure 2: Left-hand side: thickness of compressible clay deposits in Mexico City's lakebed zone. Right-hand side: subsidence rate in Mexico City's lakebed zone.

\section{Predicting procedure}

Pumping operations in Mexico City have varied over the years, making difficult the prediction of subsidence effects. Nevertheless, assuming the present pumping conditions will be maintained in the near future, useful estimations may be made as to changes expected in the existing microzoning map and the corresponding design spectra. With the information that has been presented, a year-by-year incremental procedure can be implemented for predicting the evolution of site period, as follows:

- For a given site, the initial dominant period $T_{s}^{1}$ is taken from fig. 1.

- By application of eqn. (1), calculate the initial thickness of sediments $H_{s}^{1}$ corresponding to $T_{s}^{1}$.

Then,

- Calculate the subsidence rate $v_{s}^{i}$ by use of eqn. (2).

- Calculate the amount of compaction as $\Delta H=v_{s}^{i} \Delta t$, which for $\Delta t=1$ year represents the annual subsidence.

- Calculate the change in thickness of sediments as $H_{s}^{i+1}=H_{s}^{i}-\Delta H$.

- From eqn. (1), calculate the change in site period as $T_{s}^{i+1}=\left(H_{s}^{i+1} / 31\right)^{2}+0.5$.

- Replace $i$ by $i+1$ and repeat the process for successive time steps until the target exposure period is reached.

Let us now illustrate the application of the proposed procedure for estimating the changes expected in the microzoning map of the city for the next 50 years. Fig. 3 exhibits the modified isoperiod curves by the effects of regional subsidence. The main variations are observed at the airport, Xochimilco and 
Tlahuac areas, where long site periods undergo drastic reductions. In contrast, the border between the transition and soft zones experiences little modification. The evolution of site period can be appreciated in fig. 4 for sites with current values of $T_{s}=1$ to 5 .

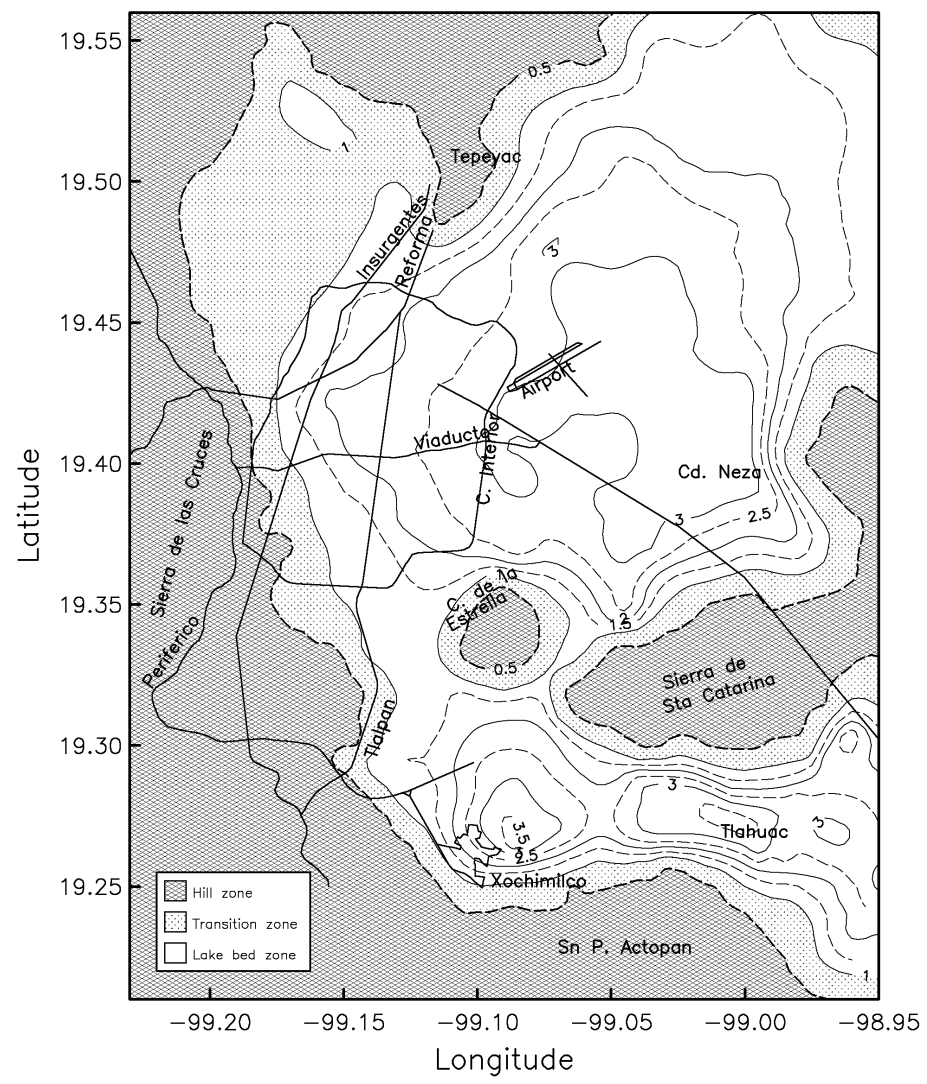

Figure 3: Modified isoperiod curves by the effects of regional subsidence for a time period running from 2000 to 2050 .

\section{Evolution of seismic hazard}

The Valley of Mexico is affected by earthquakes having different causes. They have been divided in four groups, namely: 1) local earthquakes, 2) continental plate earthquakes, 3) intermediate depth earthquakes and 4) subduction earthquakes. For the contribution of all these events, the expected Fourier amplitude spectrum at firm ground for a 125-year return period has been estimated with the use of a standard probabilistic approach. This result is shown in fig. 5 . 


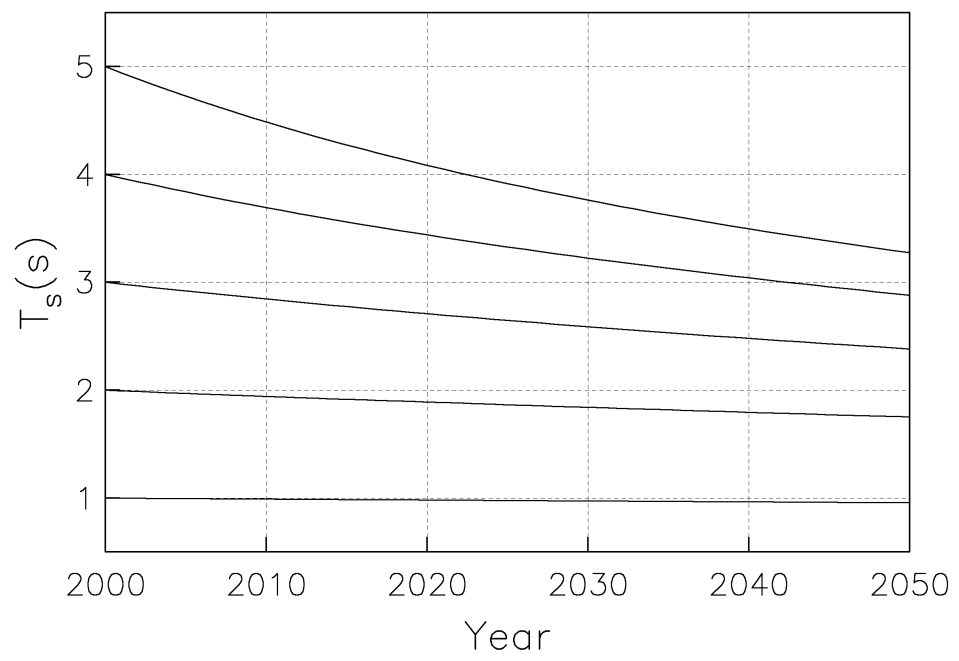

Figure 4: Evolution of site period in Mexico City's lakebed zone for a time period running from the 2000 to 2050 year.

The site effects due to local soil conditions have been explicitly considered in the Mexican Building Code [5] after the great 1985 Michoacan earthquake. The resulting site-specific design spectra are defined by the following expressions:

$$
\begin{gathered}
S_{a} / g=\frac{1+3 T_{e} / T_{a}}{4} c, \quad \text { if } T_{e}<T_{a}, \\
S_{a} / g=c, \quad \text { if } T_{a} \leq T_{e} \leq T_{b}, \\
S_{a} / g=\left(\frac{T_{b}}{T_{e}}\right)^{r} c, \quad \text { if } T_{e}>T_{b} .
\end{gathered}
$$

where $S_{a}$ is the spectral acceleration expressed as a fraction of gravity, $r=1$ for the lakebed zone of Mexico City, $T_{a}$ and $T_{b}$ are the lower and upper periods of the flat part of the spectrum, respectively, and $c$ is the seismic coefficient. The flat part of the spectrum is specified by the limiting periods

$$
\begin{gathered}
T_{a}=\max \left(0.35 T_{s}, 0.64 \mathrm{~s}\right), \text { for } T_{s}>1 \mathrm{~s}, \\
T_{b}=1.2 T_{s} .
\end{gathered}
$$

while the seismic coefficient is specified as

$$
c=\frac{4 T_{s}}{4+T_{s}^{2}}
$$


These spectra are intended to cover not only the resonant peak response associated with the first soil period, but that with the second period as well.

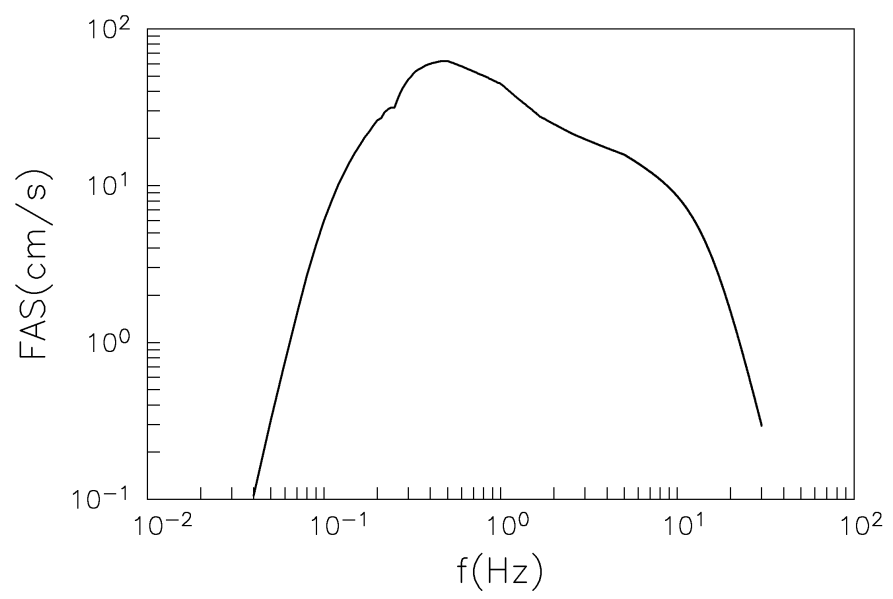

Figure 5: Fourier amplitude spectrum at firm ground in Mexico City for a 125year return period, including the effect of earthquakes from different origins.

To illustrate the evolution of code design spectra, a characteristic site with current value of $T_{s}=3.5 \mathrm{~s}$ was selected. The shortened site period resulting for an exposure period of 50 years is seen from fig. 4. A comparison between the 2000 and 2050 design spectra is made in fig. 6. Also shown are the corresponding response spectra obtained by using as input motion the Fourier amplitude spectrum of fig. 5 . The structural response was computed by applying the random vibration theory [6] to a simplified model consisting of a one-story structure placed on a uniform stratum under vertically incident shear waves, corrected empirically to account for the bedrock flexibility [7]. Although the representation is not perfect, the design spectrum intends to reproduce the general trends observed in the response spectrum, for both present and future geotechnical conditions. It is seen that regional subsidence will have either favorable or unfavorable effects on the seismic safety of existing buildings, depending primarily on the period ratio of structure and site.

The peak structural response can be conveniently represented by means of spectral contours of acceleration expressed in terms of the structure and site periods. In this way, the maximum response of any building at any location may be readily estimated. We computed the 2000 and 2050 spectral contours, the comparison of which is shown in fig. 7. They are constructed from site-specific design spectra specified by the building code throughout the whole city. Each site spectrum can be recovered by drawing a section along the site period of interest. 
464 Geo-Environment and Landscape Evolution II

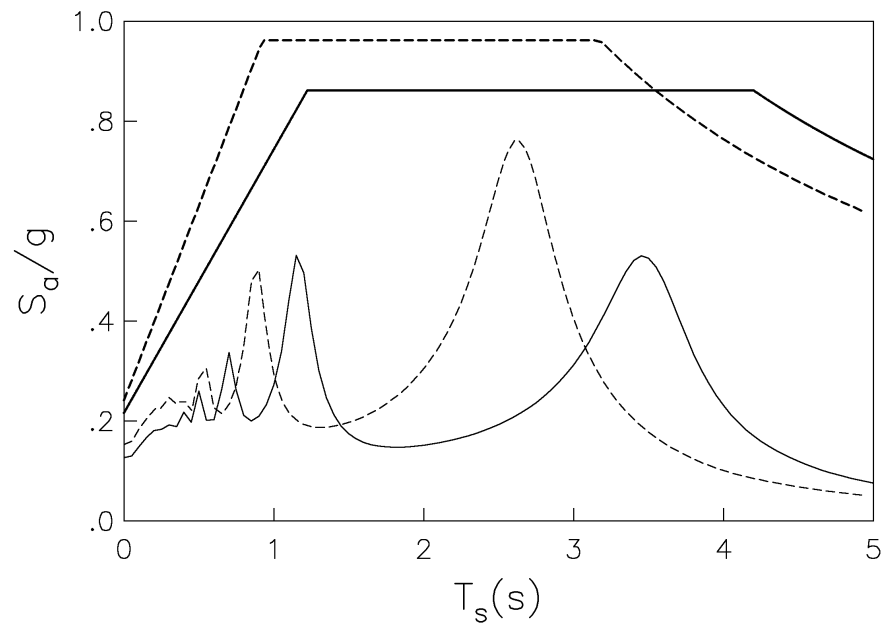

Figure 6: Comparison between the 2000 (solid line) and 2050 (dashed line) spectra for a site with presently dominant period $T_{s}=3.5 \mathrm{~s}$; design spectra (thick line) versus response spectra (thin line).

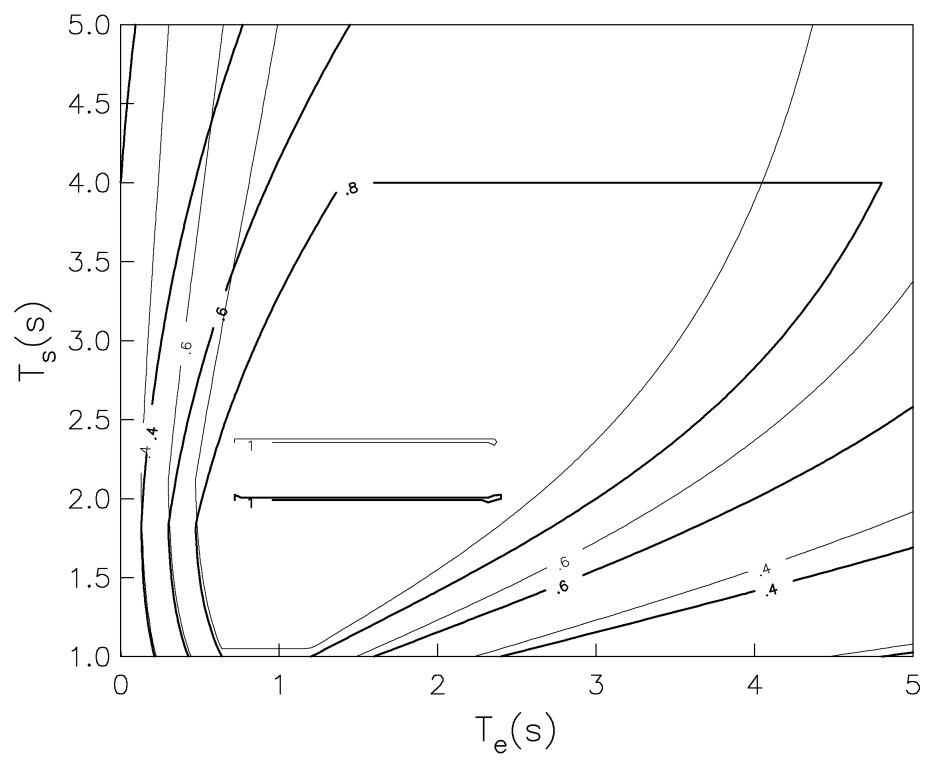

Figure 7: Comparison between the 2000 (thick line) and 2050 (thin line) spectral contours of acceleration expressed as a fraction of gravity.

Looking at the current site spectra, notice that the plateau width is an increasing function of the site period. This is to cover the influence not only of the first mode of vibration of the soil, but of the second mode as well (see fig. 6). 
In fact, the peak response associated to the latter may be as large as that associated to the former for long site periods, say, $T_{s}>3.5 \mathrm{~s}$. Also, it is apparent that the plateau height increases with the site period for $T_{s}<2 s$, but decreases for $T_{s}>2 s$. Thus, the most vulnerable buildings would be those with roughly 20 stories, assuming a fundamental period of $0.1 s$ per story. Nevertheless, this is true for the time being but not for the coming years.

The difference between the 2000 and 2050 spectral contours reflects the effects of regional subsidence. The 2050 spectral contours tend to rotate counterclockwise and elongate with respect to those for the 2000 year. Note that sites with $T_{s}>2 s$ will migrate in the future to the region in which spectral ordinates reach their peak values.

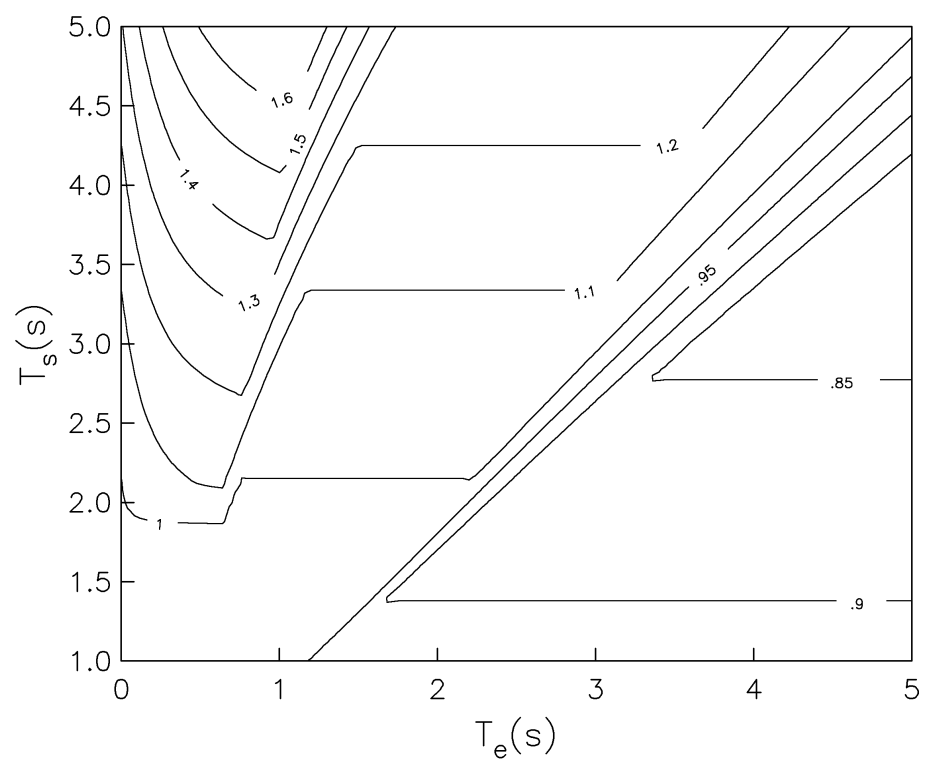

Figure 8: Subsidence impact on seismic base-shear coefficient: ratio of the 2050 to 2000 spectral contours given in fig. 7 .

To have a whole scenario for the changes expected in the seismic hazard of the city, the ratio $\alpha=S_{a}(2050) / S_{a}(2000)$ was computed. Fig. 8 shows a general view of the subsidence impact on base-shear coefficient. Both detrimental $(\alpha>1)$ and beneficial $(\alpha<1)$ effects are observed, depending on the period ratio of structure and site. For any structure and site configuration, the subsidence impact may be assessed directly from this figure, entering with the corresponding structure and site periods. It can be seen that, in general, regional subsidence will affect the structural seismic safety adversely for $T_{e}<T_{s}$ and positively for $T_{e}>T_{s}$. 


\section{Conclusions}

In this prospective study, the effects of regional subsidence on the seismic hazard for Mexico City were examined. For an exposure period of 50 years, changes expected in the existing microzoning map and the corresponding design spectra specified by the building code were assessed. In view of complexity for making an accurate prediction, only approximations were established about the magnitude of subsidence effects. After some numerical evaluations, the following main conclusions can be drawn:

a) Long site periods will undergo large reductions (e.g., from $T_{s}=5$ to $\approx 3.25 s$ ), whereas short site periods will undergo small reductions (e.g., from $T_{s}=1$ to $\approx 0.95 \mathrm{~s}$ ).

b) Sites with dominant period $T_{s}>2 s$ will migrate in the future to the region in which spectral ordinates reach their peak values.

c) In general, regional subsidence will affect the structural seismic safety adversely $(\alpha>1)$ for $T_{e}<T_{s}$ and positively $(\alpha<1)$ for $T_{e}>T_{s}$.

The assessment of subsidence effects was made in an environment of high uncertainty, where data may change rapidly from time to time due to local pumping conditions. Although the results are location specific, the predicting procedure may be applicable to other geographic locations facing similar problems of land subsidence due to ground water extraction.

\section{References}

[1] Carrillo N., Influence of artesian wells in the sinking of Mexico City, Proc. 2nd Int. Conf. on Soil Mechanics and Foundation Engineering, Rotterdam, Holland, 1948.

[2] Ovando-Shelley E., Romo M. P., Contreras N. and Giralt A., Effects on soil properties of future settlements in downtown Mexico City due to ground water extraction, Geofísica Internacional, 42, pp. 185-204, 2003.

[3] Aguilar H. R., Galicia M., Pérez-Rocha L. E., Avilés J., Vieitez L. and Salazar M., Effect of regional subsidence on dynamic soil properties, Proc. 12th Panam. Conf. on Soil Mechanics and Geotechnical Engineering, Boston, USA, 2003.

[4] Pérez-Rocha L. E., Ordaz M. and Sánchez-Sesma F. J., Spatial interpolation of seismic data: the case of the Valley of Mexico, Proc. 10th Panam. Conf. on Soil Mechanics and Foundation Engineering, Guadalajara, Mexico, 1995.

[5] MBC, Complementary Technical Norms for Earthquake Resistant Design, Mexico Building Code, Federal District Government, 1987.

[6] Boore D. M. and Joyner W. B., A note on the use of random vibration theory to predict peak amplitudes of transient signals, Bulletin of the Seismological Society of America, 74, pp. 2035-2039, 1984.

[7] Avilés J. and Pérez-Rocha L. E., Site effects and soil-structure interaction in the Valley of Mexico, Soil Dynamics and Earthquake Engineering, 17, pp. 29-39, 1998. 